\title{
INFLUÊNCIA DO ESTIOLAMENTO E DO ÁCIDO INDOLEBUTÍRICO NA FORMAÇÃO DE RAÍZES DO ALPORQUE DE CAJUEIRO ANÃO PRECOCE (ANACARDIUM OCCIDENTALE L.)
}

Francisco Célio Guedes Almeida', Francisco Aécio Guedes Almeida' Francisco Flávio Guedes Almeida ${ }^{2}$

Paulo Rogério de Carvalho ${ }^{2}$

RESUMO - O cajueiro é uma planta geralmente propagada por semente. Sua multiplicação vegetativa ainda não é comercialmente viável. Neste estudo os efeitos do estiolamento e do ácido indolebutírico (AIB) na formação de raízes do alporque da planta de caju foram investigados. O estiolamento foi realizado 30 dias antes do início do processo de alporquia. Por ocasião do anelamento do ramo, o AIB foi aplicado. Após 30 dias da realização da alporquia, os ramos já enraizados foram removidos da planta progenitora. Em seguida foram colocados em saco plástico na casa de vegetação sob condições de irrigação intermitente. Os resultados sugeriram um prévio estiolamento do ramo antes do processo de alporquia e uma aplicação de AIB, por ocasião do anelamento para, garantir a sobrevivência do alporque após o desmame.

Palavras-chave: Cajueiro, propagação vegetativa, alporquia, substância de crescimento.

ABSTRACT - The Cashew tree is usually propagated by seed since vegetative multiplication has not been fully satisfactory. In this work the effects of etiolation and AIB on air layered branches of the cashew tree were studied. Previous to airlayering procedure, the branches were etiolated during 30 days. The AIB was applied when the bark of the stem was cut. After 30 days the layers were removed from the parent plant at which roots stage were observed through the transparent bag. The rooted layers were planted in polyethylene bags and placed in a greenhouse under an intermitent-mist water spray condition. The results show that the previous etiolation and application of AIB to the exposed wound were beneficial to increase rooting and survival of cashew air layers.

Key-words: cashew, vegetative propagation, airlayering, growth substance.

1 - Professor da Universidade Federal do Ceará. Caixa Postal 12.168. CEP 60.355, Fortaleza - Ceará. Bolsista de Pesquisa do CNPq.

2 - Bolsista de Aperfeiçoamento do CNPq. 


\section{Introdução}

O cajueiro é uma planta bastante difundida nas Regiões Tropicais do mundo. O processo normalmente empregado na propagação é o sexual, devido os processos vegetativos ainda não terem alcançado os resultados desejados para um plantio comercial. Conforme Almeida (1988) a propagação vegetativa do cajueiro apresenta as seguintes vantagens: multiplicação de plantas de patrimônio genético superior; indução de precocidade; diminuição do porte. Estas vantagens tornam possível o cultivo do cajueiro, com o uso de técnicas modernas e racionais mais adequados. Os métodos de propagação assexuados utilizados no cajueiro são: estaquia, enxertia e alporquia. A alporquia ou mergulha aérea, que é o tema principal deste trabalho, é um processo vegetativo no qual o substrato usado para o enraizamento é levado até o ramo da planta que deseja propagar. Este método já vem sendo usado para propagar um grande número de plantas tropical e subtropical (Sutton, 1954; Barnes, 1974; Neel, 1979; Hare, 1979). Segundo Nagabhushanam e Murthy (1979), a alporquia é um processo simples de fácil execução, embora não seja economicamente viável. Visando obter-se a economicidade para o método, estudos estão sendo executados no Centro de Ciências Agrárias na Universidade Federal do Ceará, utilizando técnicas mecânicas e químicas na tentativa de estimular uma melhor formação do sistema radicular do alporque e assim alcançar uma maior taxa de sobrevivência após o desmame.

\section{Resultados e discussão}

A alporquia de maneira convencional, não vem apresentando efeitos satisfatórios em cajueiro, uma vez que os alporques formam um sistema radicular composto unicamente de raízes de fixação. Na propagação assexual por estaca, o estiolamento é uma prática eficiente para induzir a formação de raízes adventícias (Frolich, 1961). Hartmann e Kester (1983), reportam que a luz tem efeito inibitório na iniciação de raízes. O processo de inibição embora não sendo totalmente conhecido, os autores acreditam na possibilidade da luz interferir no conteúdo endógeno das auxinas, responsável pelo início da formação do sistema radicular. Assim sendo o estiolamento e o ácido indolebutírico foram utilizados na tentativa de induzir um sistema radicular mais eficiente. Neste estudo utilizou-se 40 ramos terciários, de 30 a $40 \mathrm{~cm}$ de comprimento com $1 \mathrm{~cm}$ de diâmetro, de diferentes plantas de cajueiro anão precoce do "Campus" do PICI da Universidade Federal do Ceará, em Fortaleza. Destes, 20 foram submetidos a um estiolamento, com fita preta adesiva, numa extenção de $3 \mathrm{~cm}$, durante 30 dias. Os ramos estiolados e os não estiolados foram submetidos ao processo de alporquia. Dez estiolados e 10 não estiolados foram tratados com 250ppm de AIB, no local do anelamento do ramo. Transcor- 
ridos 30 dias da realização dos alporques, foi feito o desmame. Observou-se que $40 \%$ do tratamento sem hormônio e sem estiolamento iniciou a formação de um sistema radicular, porém sem condições de sobrevivência, já que pereceram antes do transplantio para o local definitivo. No tratamento sem estiolamento e com aplicação do AIB, $80 \%$ dos alporques formaram o sistema radicular, embora também sem condiçōes de sobrevivência. Quando os ramos foram apenas estiolados, $100 \%$ dos alporques formaram sistema radicular e $89 \%$ dos quais sobreviveram após o transplantio para o campo. Cem por cento dos ramos estiolados e tratados com AIB apresentaram sistema radicular e $86 \%$ sobreviveram nas condições de campo. A análise estatística mostrou uma diferença não significativa para os tratamentos utilizados, no que se refere aos percentuais de formação de raízes. Mesmo na ausência do AIB, o estiolamento foi capaz de induzir um sistema radicular adequado à sobrevivência do alporque após o transplantio para o campo. Sem um prévio estiolamento o AIB não induziu formação de raízes absorventes. Na ausência destas, os alporques pereceram antes do transplantio. Embora não apresentando significância, os resultados demonstraram a importância de um prévio estiolamento, quando se pretende aplicar o AIB visando a formação dos sistemas secundários e terciários de raízes. Sem estes sistemas tornou-se impossível a sobrevivência do alporque de cajueiro. Semelhante resultado foi encontrado por Herman e Hess (1961), em estudos de estaquia em feijoeiro, quando o tecido estiolado apresentou uma reação positiva para a formação de raízes na presença do AIB.

\section{Referências bibliográficas}

ALMEIDA, J.I.K., 1988. Métodos de propagação. I: A cultura do cajueiro no Nordeste do Brasil. Bє nco do Nordeste do Brasil S/A. pp. 119-158.

BARNES, R.D. 1974. Air-layering of grafts to overcome incompatibility problems in propagating old pine trees. New Zealand Jour. For. Sci. 4(2): $120-126$.

FROLICH, E.F. 1961. Etiolation and the rooting of cuttings. Proc. Inter. Plant. Prop. Soc. 11:277-283.

HARE, R.C. 1977. Rootins of cuttings from mature water oak (Quercus nigra). Southern Jour. Appl. For. 1(2):24-25.

HARTMANN, H.T. \& D.E. HESTER 1983. Plant propagation principles and practices. New Jersey, Prentice-Hull.

HERMAN, D.E. \& C.E. HESS. 1963. The effect of etiolation upon the rooting of cuttings. Proc. Inter. Plant. Prop. Soc. 13:42-62.

NAGABHUSHANAM, S. \& K.N. MURTHY. 1979. Prospects of vegetative propagation of cashew (Anacardium occidentale L.) by air-layering. Indian Cashew Journal 12:29-32.

NEEL, P.L. 1979. Macropropagation of tropical plants as praticed in Florida. 
Proc. Inter. Plant. Proc. Soc. 29:468-480.

SUTTON, N.E. 1954. Marcotting of persian limes. Proc. Fla. State. Hort. Soc. 67:219-220. 